\title{
Influence of tides and tidal current on Mertz Glacier, Antarctica
}

\author{
Benoît LEGRÉSY, ${ }^{1}$ Anja WENDT, ${ }^{2 *}$ Ignazio TABACGO ${ }^{3}$ FrédÉrique RÉMY, ${ }^{1}$ \\ REINHARD DIETRICH ${ }^{2}$ \\ ${ }^{1}$ Legos (CNES-CNRS-UPS-IRD), 18 Av. Edouard Belin, 31401 Toulouse Cedex, France \\ E-mail: benoit.legresy@cnes.fr \\ ${ }^{2}$ Institut für Planetare Geodäsie, Technische Universität Dresden, D-01062 Dresden, Germany \\ ${ }^{3}$ Dipartimento di Scienze della Terra, Sez. Geofisica, Università degli Studi di Milano, Via Cicognara 7, I-20129 Milan, Italy
}

\begin{abstract}
Mertz Glacier, East Antarctica, is characterized by a $140 \mathrm{~km}$ long, $25 \mathrm{~km}$ wide floating ice tongue. In this paper, we combine a large number of remotely sensed datasets, including in situ global positioning system measurements, satellite radar altimetry, airborne radio-echo sounding and satellite synthetic aperture radar imagery and interferometry. These various datasets allow us to study the interaction of the ice tongue with the tides and currents. However, the inverse barometer effect needs to be applied to sea-level variations affecting the tongue. We find that the tide-induced currents exert a small lateral pressure on the tongue which, when integrated over the large surface of the tongue, induce a flexure of up to $2 \mathrm{~m}$ amplitude per day. Simple elastic modelling of the flexure confirms the observations and helps validate the boundary conditions necessary to explain different eastward and westward tongue deflections. In addition, the along-flow velocity of the tongue does vary daily from 1.9 to $6.8 \mathrm{~m} \mathrm{~d}^{-1}$ depending on the tidal current. When the current pushes the tongue toward the eastern boundary of the fjord, the tongue is retarded by the drag and the velocity decreases. The accumulated stress is released, allowing the tongue to flow very rapidly when the current pushes the tongue westward. These forcing and boundary conditions on the floating ice flow are important and must be taken into account when studying glacier discharge and calving.
\end{abstract}

\section{INTRODUCTION}

The George V Coast of East Antarctica has three main glacier outflows: Mertz and Ninnis Glaciers and the Cook Ice Shelf. They have the peculiarity of producing large ice tongues several tens of $\mathrm{km}$ long which sometimes break up, as occurred at Ninnis Glacier in 1999/2000. These tongues regularly produce large icebergs, which ground on the shallow waters of the continental margin.

These large ice tongues were first reported by the Australian expedition of 1911-14 led by Sir D. Mawson. A Soviet expedition in 1957 resurveyed the region and showed large changes in size and shape of the Mertz and Ninnis tongues. The Deep Freeze 79 expedition helped map the bathymetry of the area more precisely (Domack and Anderson, 1983). The bathymetry of the area is characterized by the presence of a deep valley running parallel to the coast, the George V Basin where the water depth reaches $1000-1400 \mathrm{~m}$. A large continental margin extends $150 \mathrm{~km}$ north of the present-day coast, with water depths of a few hundred metres. The continental margin also comprises banks of shallow water, such as the Mertz and Ninnis banks, which are preferential resting areas for large icebergs calved by the ice tongues. This cyclical release of large ice masses is found to play a major role in the

*Née Pötzsch. sedimentation and shaping of the continental margin (Barnes, 1987; Domack, 1987).

There have been several attempts to measure the ice discharge of these glaciers, including that by Frezzotti and others (1998), who estimated the accumulated discharge of Mertz and Ninnis Glaciers to be $62 \mathrm{Gt} \mathrm{a}^{-1}$ and the accumulated ice in the drainage basin to be $58 \mathrm{Gt} \mathrm{a}^{-1}$. In this study, we concentrate on the Mertz ice tongue (Fig. 1), which extends over $140 \mathrm{~km}$ from the grounding line to the front, with a width of $30 \mathrm{~km}$ at the front edge.

Wendler and others (1996) estimated a flow velocity of $1 \mathrm{~km} \mathrm{a}^{-1}$ on the ice tongue by picking details on repeated Japanese Earth Resources Satellite 1 (JERSl) synthetic aperture radar (SAR) images and comparing the tongue front position with former observations. Pötzsch and others (2000) derived the grounding-line position and the topography of the tongue basin using SAR interferometry, and reported good agreement between the observed and modelled tides.

The study of tidal interaction with the floating ice has a long history. Holdsworth (1969) set the formalism of the vertical flexure of a floating ice tongue due to tidal forcing and questioned the type of interaction to use (elastic or plastic). More recently, simultaneous measurements of tide and ice flow show that there must be some link between the tide level and the ice velocity of glaciers on the floating part of the ice shelf. Riedel and others (1999) used the global positioning system (GPS) to study the ice flow on the grounding 


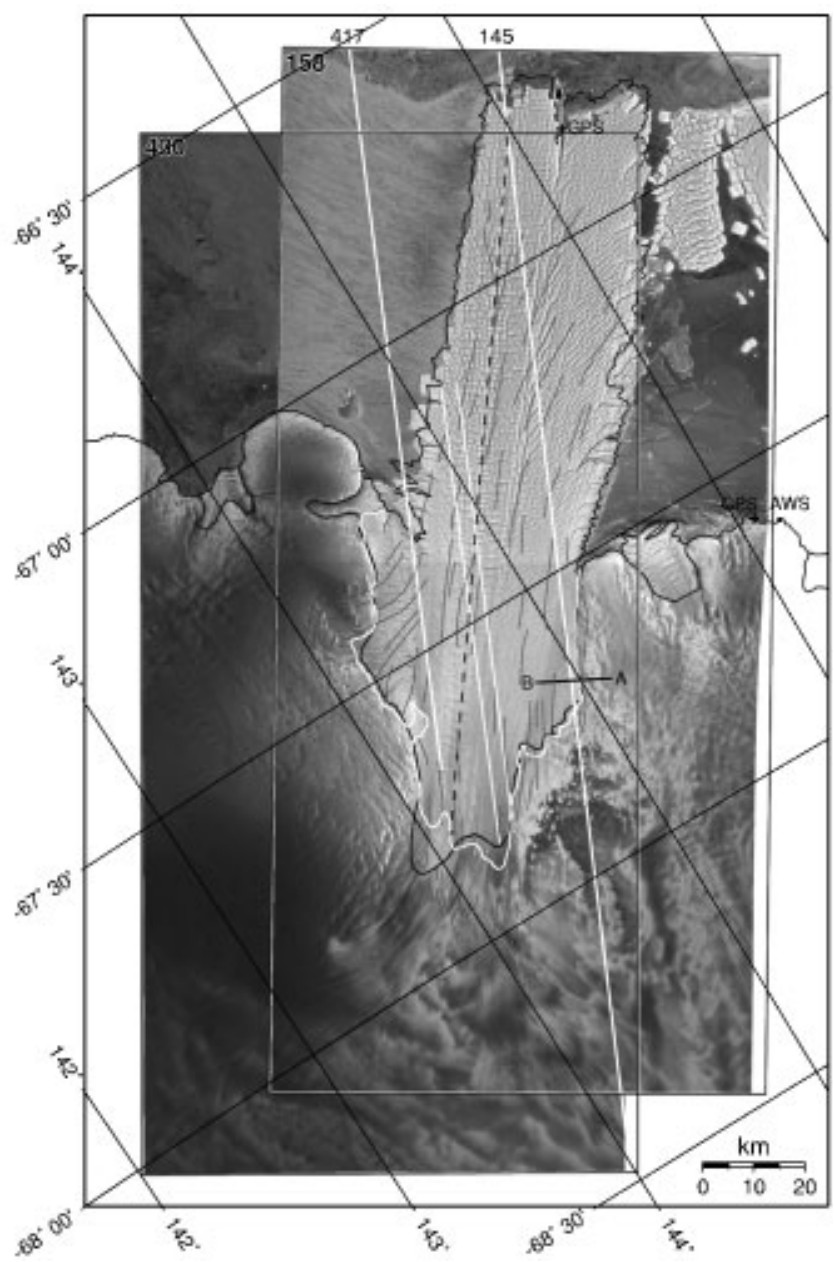

Fig. 1. ERS SAR mosaic of the Mertz Glacier area. European Space Agency single look complex data were used to make this high-resolution mosaic. Straight white lines correspond to altimeter tracks, and the straight black dashed line to the radioecho sounding (RES) profile. The frames of the SAR scenes are indicated, and section $A-B$ corresponds to the profile used to fit the tidal vertical bending. The curved white line corresponds to the grounding-line position recovered from the interferograms, the curved black line to the coastline and grounding line given in the Antarctic Digital Database, and the straight black dashed line to the RES flight-line. The black dotted lines correspond to the boundary of the ice tongue considered as effective for the mechanical bending.

zone of Ekströmisen, Dronning Maud Land, Antarctica. They found a clear influence of the ocean tides on the ice movements on the floating part and at least $1 \mathrm{~km}$ upstream of the grounding line. They found that high/low tides imply a landward/seaward movement.

Doake and others (2002) used 30 days of continuous GPS observations on the Brunt Ice Shelf and found that tides influenced the lateral movement of the ice shelf with a delay between the vertical tidal movement and the horizontal tide-linked movement. Anandakrishnan and others (2003) found a very strong modulation of the flow speed of Ice Stream D due to the tide beneath the Ross Ice Shelf. Finally, Bindschadler and others (2003a) observed a link between tides and the flow of Ice Stream B, invoking a stick-slip driven motion. They observed that the motion events did not correspond to high tides and did not relate generally to tides in a simple way. They came to the conclusion that an elastic strain storage-and-release mechanism, depending on the tide level (Bindschadler and others, 2003b), helps explain the relation between tides and flow variations. Bindschadler and others (2003a) mention the possibility that tidal currents play a role in the floating ice movement by drag below the ice.

In the present paper, we concentrate on studying the interaction between the Mertz ice-tongue flow and the ocean tides and currents. Firstly, we describe our complete set of observations. We study the effect of an ocean current intersecting laterally with the tongue flow direction, using the formalism of an elastic tongue flexure. We then show that our observations can be explained by a lateral tidal current, and we discuss the implications for the ice-tongue flow and break-up.

\section{DATASETS}

We used four types of remotely sensed data to estimate the ice displacements. Vertical displacements were estimated using the FES99 ocean tide model (Lefevre and others, 2002) and the inverse barometer effect (IBE) based on pressure measurements from the nearby automatic weather station (AWS) at Penguin Point (http://uwamrc.ssec.wisc.edu/ aws/awsdata.html). All of the vertical displacements will be compared to this (Tide+IBE) reference. The locations of the available data are shown in Figure 1.

\subsection{Radio-echo sounding (RES) data}

In 2000 a survey of the George V Coast was made by the Italian Antarctic Expeditions. In particular, a profile was acquired along the Mertz tongue from the ice-shelf front up to the grounded area (dashed line in Fig. 1). The $60 \mathrm{MHz}$ central frequency and $16 \mathrm{MHz}$ bandwidth radar were mounted on an airplane. Laboratory tests give a $10 \mathrm{~m}$ error for the radar measurements. A noisy signal was obtained over the tongue, perturbed by the large crevasse patterns, and this can increase the error by up to $100 \mathrm{~m}$ in some places. The profile is, however, continuous along the ice tongue. Cross-checking between altimetric height and RES data, assuming hydrostatic equilibrium and a mean ice density of 0.9 , gave us confidence in both datasets and revealed that, at least up to longitude $145^{\circ} \mathrm{E}$, the tongue can be considered as composed of pure ice. This can easily be understood given the strong winds which flow down the coast in this area and erode the snowpack. The accumulation may be more important over the northern part of the tongue where the snow transported by wind is deposited on the tongue as the wind spreads over the flat ocean.

\subsection{Radar altimetry data}

The European Remote-sensing Satellite (ERS-1 and -2) radar altimeters have recorded data since 1991. Two tracks of the 35 day repeat mission cross the Mertz tongue (track numbers 145 and 417, marked in Fig. 1). Two other track segments acquired during the ERS-1 geodetic mission are also shown in Figure 1. The raw altimeter data have been processed within the OSCAR project using the retracking algorithm described by Legrésy and Rémy (1997) and used with the name Ice2 on the ENVISATradar altimetry processing chain. These data were corrected for ionospheric and tropospheric range delays. An average value was computed over a $10 \mathrm{~km}$ segment for each repeat measurement. The 

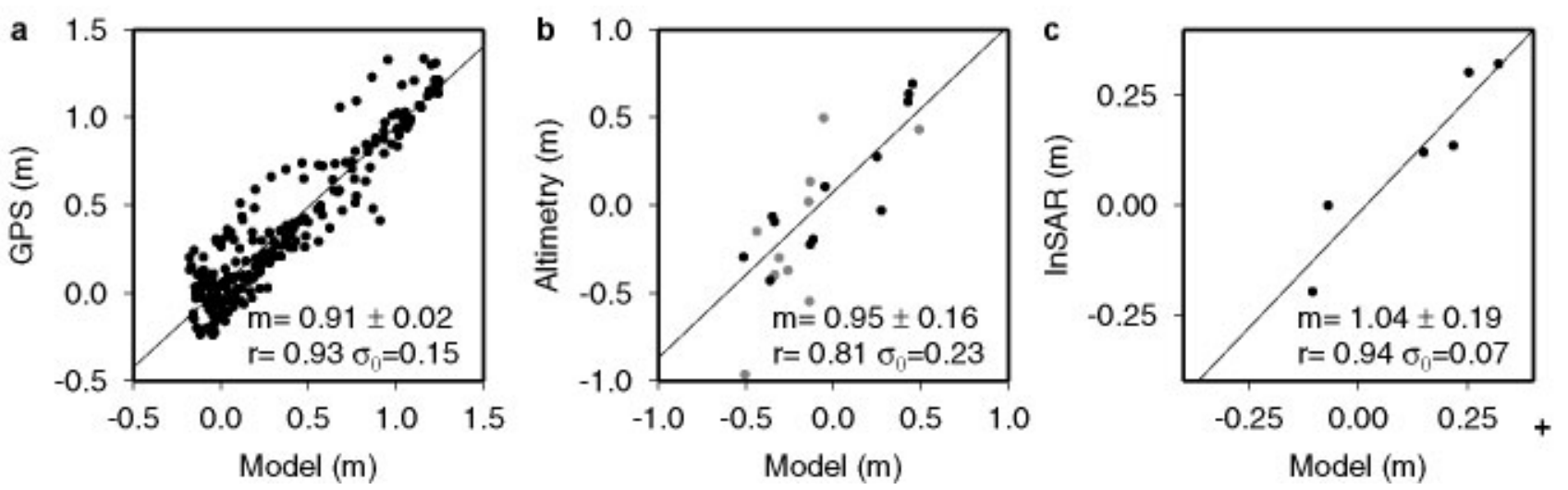

Fig. 2. Comparison of the different remote-sensing measurements of sea-level variations vs the tide (FES99 model) + IBE (computed from Penguin Point pressure gauge). All values are in m. The comparison is made with GPS data (a), ERS altimetry (b) and ERS SAR interferometry $(c) . m$ is the regression coefficient, $r$ is the correlation and $\sigma$ is the rms data dispersion.

comparison for each date with the (Tide+IBE) data shows fairly good agreement (Fig. 2).

\subsection{GPS data}

The main goal of the German Antarctic North Victoria Land Expedition GANOVEX VIII in 1999/2000 was the geological and geophysical investigation of the region. During this expedition, GPS measurements were carried out on the tip of the Mertz tongue (Korth, 2001). Due to unfavourable weather conditions, only 4 days of data, with a 1 day gap, were collected. The data were analyzed with the Bernese GPS Software version 4.2 (Beutler and others, 2001). The $85 \mathrm{~km}$ long baseline between the Mertz Glacier tongue front and Penguin Point (a fixed rock site) was solved pseudo-kinematically. An iterative approach was applied to account for the movement of the receiver within the $20 \mathrm{~min}$ time slices. For this reason, there was no need to introduce any a priori information on the horizontal and vertical movements of the ice tongue. The accuracy of the height determination was assessed by solving a static baseline in the same way. Since only the $1300 \mathrm{~km}$ long baseline (Penguin Point-McMurdo) was available for this assessment, the resulting standard deviation of $8.5 \mathrm{~cm}$ can be regarded as an upper limit. Taking into account the vicinity of the GPS observations to the magnetic pole and the maximum of solar activity resulting in ionospheric disturbances, this 8-9 $\mathrm{cm}$ upper limit for the accuracy seems reasonable. Comparison with the (Tide+IBE) data shows very good agreement (Fig. 2).

\subsection{SAR data}

We computed four interferograms using ERS-1 and -2 data acquired in 1996. Three interferograms have been shown in Pötzsch and others (2000). Table 1 summarizes all the information related to the SAR scenes that we used. All interferograms are from the tandem period (this means using 24 hour exact repeats between ERS-1 and -2), and they all correspond to descending tracks with a look direction from the southeast perpendicular to the frame direction (Fig. 1). One fringe in an interferogram corresponds to a $28 \mathrm{~mm}$ displacement in the satellite line of sight. Figure 3 shows one of these single-difference tandem interferograms. In order to retrieve the grounding line, we formed double-difference interferograms in which the remaining fringes can be attributed to the residual vertical tidal flexure of the ice beam (Rignot, 1996). The fringes observed at the grounding line

Table 1. Dates and conditions of acquisition of the SAR data

\begin{tabular}{|c|c|c|c|c|c|c|c|}
\hline Track & S_orbit & Date & $\begin{array}{c}\text { Time } \\
\mathrm{h}\end{array}$ & $\begin{array}{c}B_{\text {perp }} \\
\mathrm{m}\end{array}$ & $\begin{array}{c}\text { FES99 } \\
\text { cm }\end{array}$ & $\begin{array}{c}\text { Pressure } \\
\qquad \mathrm{hPa}\end{array}$ & $\begin{array}{c}\text { Sea level } \\
\text { cm }\end{array}$ \\
\hline 430 & $\begin{array}{l}\text { 1_23965 } \\
\text { 2_04292 }\end{array}$ & $\begin{array}{l}13 \text { Feb } 1996 \\
14 \text { Feb } 1996\end{array}$ & $\begin{array}{l}2256 \\
2256\end{array}$ & 144.3 & $\begin{array}{r}-50.13 \\
-50.11 \\
0.02\end{array}$ & $\begin{array}{l}977.0 \\
977.7 \\
-0.7\end{array}$ & $\begin{array}{r}-14.07 \\
-14.74 \\
-0.68\end{array}$ \\
\hline 158 & $\begin{array}{l}\text { 1_25196 } \\
\text { 2_05523 }\end{array}$ & $\begin{array}{l}9 \text { May } 1996 \\
10 \text { May } 1996\end{array}$ & $\begin{array}{l}2253 \\
2253\end{array}$ & 20.9 & $\begin{array}{r}-33.69 \\
-17.17 \\
16.52\end{array}$ & $\begin{array}{r}962.1 \\
953.9 \\
8.2\end{array}$ & $\begin{array}{l}17.19 \\
41.87 \\
24.72\end{array}$ \\
\hline 430 & $\begin{array}{l}\text { 1_25468 } \\
2 \_05795\end{array}$ & $\begin{array}{l}28 \text { May } 1996 \\
29 \text { May } 1996\end{array}$ & $\begin{array}{l}2256 \\
2256\end{array}$ & 20.0 & $\begin{array}{l}36.8 \\
53.57 \\
16.77\end{array}$ & $\begin{array}{l}973.0 \\
975.4 \\
-2.4\end{array}$ & $\begin{array}{l}76.91 \\
91.22 \\
14.37\end{array}$ \\
\hline
\end{tabular}

Notes: Column 1 gives the satellite pass number, column 2 the satellite orbit number, columns 3 and 4 the date and time of acquisition, column 5 the orthogonal orbit separation between the two acquisitions which fixes the sensitivity to topography. Column 6 gives the FES99 tide model for this date, and column 7 the pressure measured by AWS at Penguin Point. Column 8 gives the sea level estimated as the result of FES99 + IBE. Sea level is referenced to annual mean pressure of $972.7 \mathrm{hPa}$. Intermediate lines give the differences corresponding to the interferogram formed with the two lines above. 


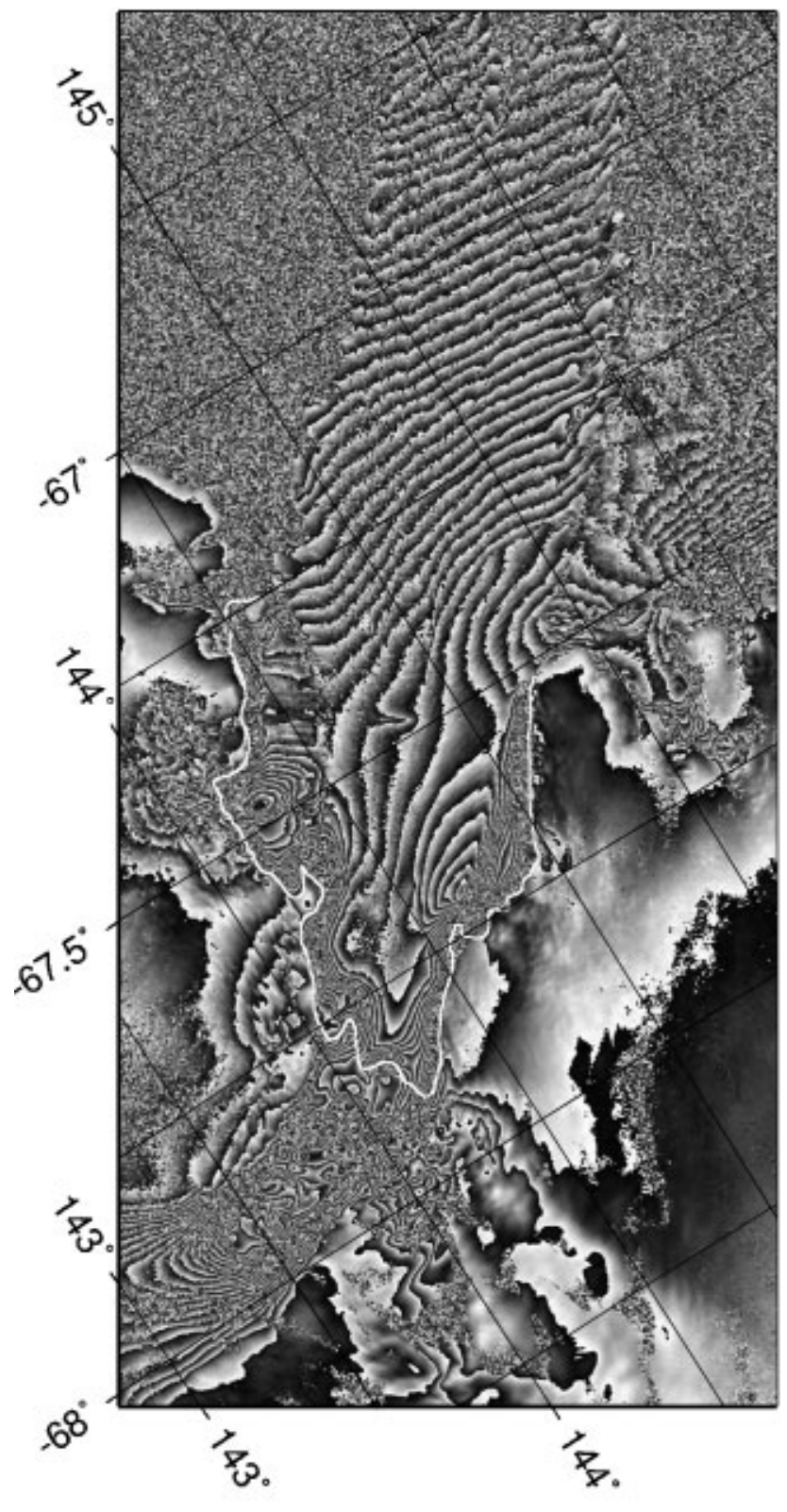

Fig. 3. Interferogram corresponding to the May (158) ERS SAR scenes. The many parallel fringes visible on the tongue reveal the horizontal flexure of the tongue in between the two acquisitions. The grounding line is drawn in white.

on these double differences do correspond to such vertical tidal flexure. Fitting this flexure as described in section 3 gives the corresponding vertical displacement. According to Table 1 , the comparison with the (Tide+IBE) shows fairly good agreement (Fig. 2). We will see in the following sections that the double-difference interferograms also compound other non-steady displacement. GPS, and SAR data are also useful for studying horizontal displacements.

\section{IGE-TONGUE MEGHANICS}

Hereafter we will consider elastic bending. Holdsworth (1969) provides the formulation that the second derivative of the bending is proportional to the bending moment. We observed horizontal bending of the tongue with both GPS and interferometric SAR (InSAR) data. Holdsworth (1985), while looking for physical processes affecting floating glacier tongues, mentioned one that can apply to the specific situation of the Mertz: ocean current action on the ice.
Effectively, the currents exert a pressure on the floating ice; this situation is investigated in this section.

We take Holdsworth's (1969) formulation and apply it to the case of a pressure force acting horizontally, orthogonal to the tongue flow, and solve it on the neutral axis running along the centre of the tongue.

If $y$ is the horizontal position perpendicular to the main direction of the tongue,

$$
y^{\prime \prime}(x)=-\frac{1-\mu^{2}}{E_{\mathrm{b}} I_{\mathrm{a}}} M(x),
$$

where $E_{\mathrm{b}}$ is the elastic modulus of the ice, $\mu$ is Poisson's ratio, taken as $0.3, M(x)$ is the bending moment and $I_{\mathrm{a}}$ is the moment of inertia. We assume that the tongue has a rectangular section with variable width $(W)$ and thickness $(H)$.

On the segment A-B shown in Figure 1 near $145^{\circ} \mathrm{E}$, we computed an ice thickness of $440 \mathrm{~m}$ from hydrostatic equilibrium and altimeter measurements, which show a flat, stable surface over a few kilometres. We computed the bending parameters of Holdsworth (1969) using double-difference interferograms, according to the method described by Rignot (1996). We computed the tide-damping factor for several parallel transects on the double-difference interferograms $\mathrm{I}_{1}$ (April (430)-May (158)) and $\mathrm{I}_{2}$ (April (430)May (430)) (see Table 1). We chose this area because the grounding line follows a straight line, so there cannot be curvature effects on the parameter estimates, such as those described by Rabus and Lang (2002). We did not observe any shift of the grounding-line position depending on the tide level, indicating that the bedrock slope must be large here. We thus consider the grounding line to be fixed throughout the tidal cycle. We estimated the grounding position, damping factor, amplitude of the tidal deflection and reference level by non-linear least-squares fitting. We estimated parameters for numerous parallel transects in the area and found the damping factor to be stable at $0.78 \mathrm{~km}^{-1}$ which leads to a realistic value for the elastic modulus of $0.88 \mathrm{GPa}$ (Vaughan, 1995). Large errors can arise for this parameter, both because the fitting minimum is not well defined by the procedure (Vaughan, 1995) and because a small error in thickness has a strong impact on the recovered $E_{\mathrm{b}}$ value $(H=440 \pm 10 \mathrm{~m}$ leads to $\left.E_{\mathrm{b}}=0.88 \pm 0.06\right)$.

To complete the scheme we computed $I_{\mathrm{a}}$ according to

$$
I_{\mathrm{a}}=\int_{-W / 2}^{W / 2} y^{2} \mathrm{~d} y=\frac{w^{3}}{12},
$$

and $M$ according to

$$
M(x)=\int_{0}^{x}(x-l) \frac{\rho_{\mathrm{i}} \nu^{2}}{2} H(l) \mathrm{d} l,
$$

where $\rho_{\mathrm{i}}$ is the ice density which we take as $900 \mathrm{~kg} \mathrm{~m}^{-3}$ and $\nu$ is the component of the water current orthogonal to the tongue causing the excess pressure. The ice thickness over which the current acts is $\mathrm{H} \rho_{\mathrm{i}} / \rho_{\mathrm{w}}$. The origin of the $x$ axis is at the front of the tongue and oriented towards the grounding zone. An additional force should come from the drag of the current below the tongue. This additional force would be proportional to $W \nu^{2}$, and it can then be taken into account by adding a drag coefficient in front of $M(x)$ in Equation (1).

The horizontal flexure of the tongue due to the pressure exerted by the ocean current is found by integrating Equation (1) twice. We set $M(x)$ at 0 on $x=0$, which means that 

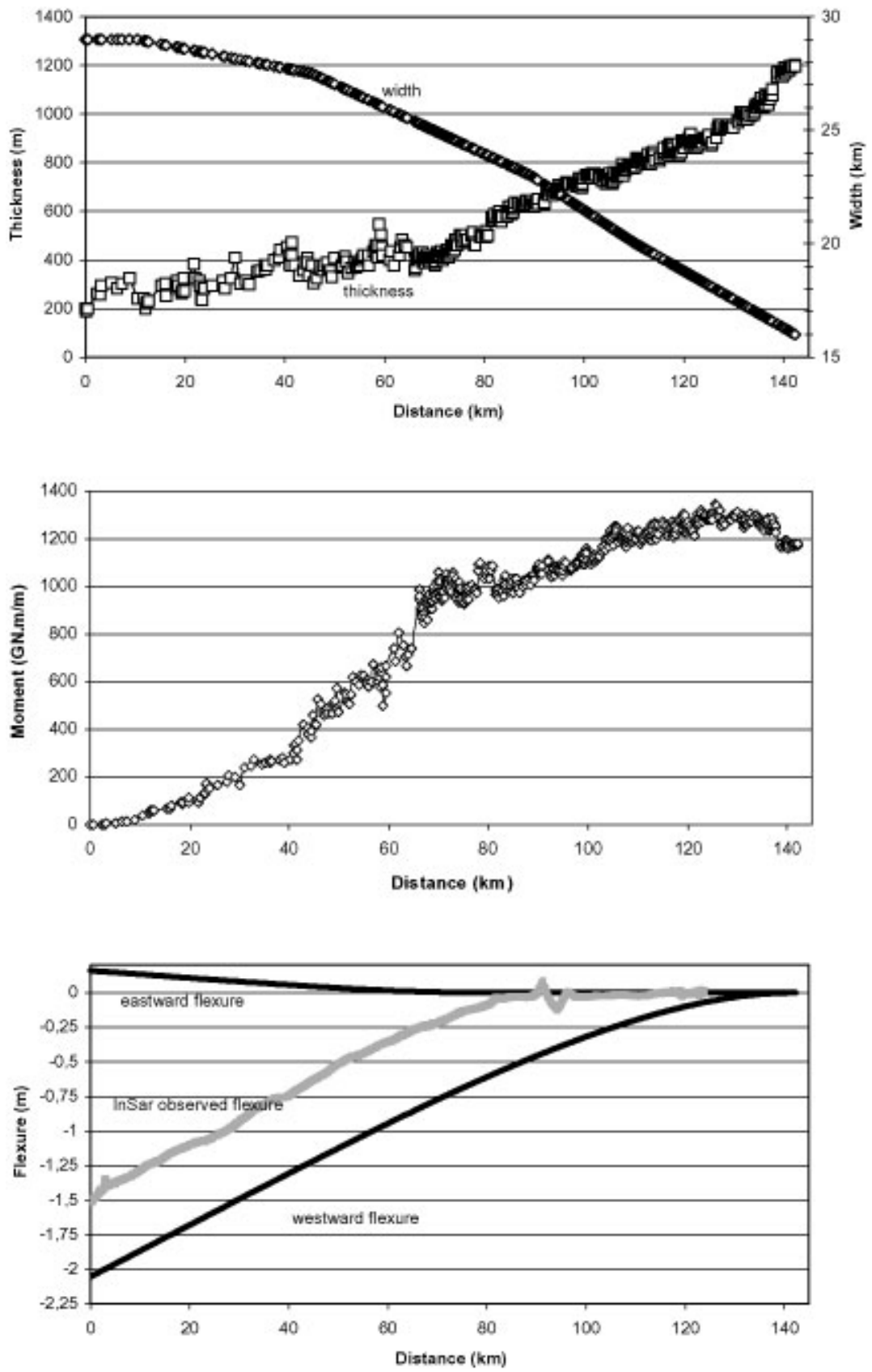

Fig. 4. Modelling the horizontal elastic flexure of the tongue for a $1 \mathrm{~m} \mathrm{~s}^{-1}$ lateral ocean current.

no lateral force is exerted on the tongue for $x<0$ since there is no tongue in this case. We also set $y(x)=0$ on the grounding line $\left(x=x_{\mathrm{g}}\right)$, and both conditions are sufficient boundary conditions for the numerical integration. This latter boundary condition is less restrictive than the former and does not presume any ice deformation upstream of the grounding line, which might occur (the latter could be assumed as negligible in front of the flexure along the $140 \mathrm{~km}$ long ice tongue). We do not investigate here the effect of coupling between vertical and horizontal flexures; however, the impact on horizontal flexure would be very small. In the case of the Mertz tongue, F. Lyard (personal communication, 2003) finds that maximum tidal currents are of the order of $0.25 \mathrm{~m} \mathrm{~s}^{-1}$ during the ascending and descending tides, using the FES99 model. This current acts on the tongue between the main shore and the tongue edge, i.e. over the first $80 \mathrm{~km}$ of the tongue.

The pressure force from the usual tide differences is of order $1 \mathrm{kPa}$, which is much larger than the pressure force exerted by the current (about $30 \mathrm{~Pa}$ ). The main difference between the horizontal flexure and the vertical flexure under tidal forcing is linked to the dimension which resists the bending. This dimension is the ice-section width for the horizontal flexure instead of the height for the vertical flexure, and ice tongues are usually much wider than they are thick. The other important difference is that there is no limitation to the horizontal bending, whilst vertical bending is limited by the tidal amplitude. Our ice flexure model will be limited by the poor knowledge of the current velocity as a function of distance along the tongue and by the unknown water/ice drag coefficient below the tongue. However, our results demonstrate the important effects which must apply. As a first case, we model the flexure assuming the thickness measured along the RES flight represents the whole crosssection. We assume the section width, which is mechanically effective, is the one that follows western and eastern flowlines at the grounding zone which are marked in Figure 1. Finally, we take into account the width variation when the 

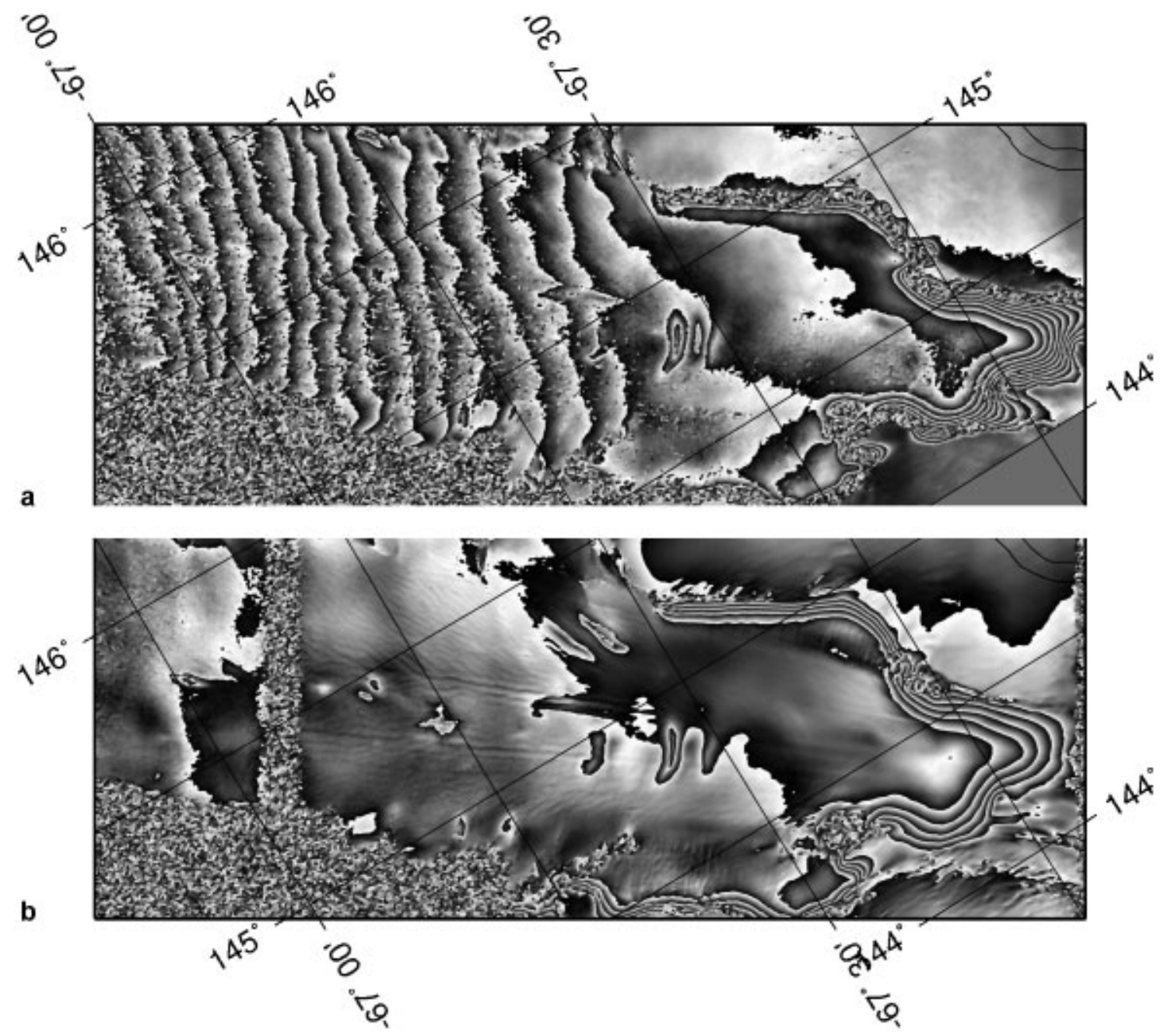

Fig. 5. Double-difference interferograms showing the horizontal flexure of the tongue. One fringe corresponds to $28 \mathrm{~mm}$ distance variation in the satellite line of sight. (a) Double difference $I_{1}$. Both verticalflexure at the grounding line and lateralflexure of the tongue are observed. (b) Double difference $I_{2}$. Mainly vertical flexure near the grounding line is present.

ice spreads (from 18 to $26 \mathrm{~km})\left(I_{\mathrm{a}}=I_{\mathrm{a}}(x)\right)$. Figure 4 shows the results of our model for a $1 \mathrm{~m} \mathrm{~s}^{-1}$ westward current applied to the first $80 \mathrm{~km}$. Since a $1 \mathrm{~m} \mathrm{~s}^{-1}$ current is used in the model, changing the current to $\nu$, one must scale the result by $\nu^{2}$. Since the thickness increases in the second part of the tongue and no more pressure is applied, the momentum does not increase significantly from the shoreline to the grounding line. Figure $4 \mathrm{a}$ shows the width and thickness profile used for the flexure computation. Figure $4 \mathrm{~b}$ shows the momentum per thickness unit profile computed according to Equation (3). Figure 4c shows the bending computed for both the eastward and westward current. We obtain a $2.1 \mathrm{~m}$ lateral displacement of the edge of the tongue for a $1 \mathrm{~m} \mathrm{~s}^{-1}$ westward current or $0.13 \mathrm{~m}$ for the $0.25 \mathrm{~m} \mathrm{~s}^{-1}$ maximum current obtained with FES99. Note that significant bending arises mainly from the shoreline to the edge, where the current is most effective.

\section{OBSERVATIONS OF THE TONGUE BENDING}

\subsection{Horizontal bending from InSAR observations}

Looking at InSAR double differences $I_{1}$ and $I_{2}$ (Fig. 5), we can see that fringes corresponding to lateral displacements are present. Sixteen fringes can be counted on $\mathrm{I}_{1}$ while only three are seen on $\mathrm{I}_{2}$. According to the projection of the displacement in the satellite line of sight, we find $1.15 \mathrm{~m}$ horizontal bending for $\mathrm{I}_{1}$ and $0.21 \mathrm{~m}$ for $\mathrm{I}_{2}$. This difference can be explained by the fact that the May (track 158) interferogram corresponds to a $17 \mathrm{~cm}$ tide difference with the ERS-2 acquisition at a tide level of $-17 \mathrm{~cm}$ (Table 1), the nearest to tide level 0 of all of the eight acquisitions. Tide level 0 corresponds to the largest tidal current (linked to the divergence of the tide-level time variations). Thus, the horizontal bending of the ERS-2 orbit 05523 acquisition will be the largest of the eight available scenes. The observed parallel fringes in $\mathrm{I}_{1}$ are thus in agreement with a horizontal bending following tidal currents, with values comparable to the model for a $0.74 \mathrm{~m} \mathrm{~s}^{-1}$ lateral current. This is three times greater than the expected maximum current speed, and the tide differences of $I_{1}$ may not lead to the maximum tidalcurrent speed difference. Either the current drag under the tongue must be at least twice the lateral pressure force, or another source of deformation must lead to this large number of fringes. The linear fringe pattern reveals that the tongue is flexing in phase, even though it is $20 \mathrm{~km}$ wide. It also has a linear trend (regular fringes), which implies a linear bending which is effectively modelled (Fig. 4). In Figure $4 \mathrm{c}$, we put the profile of effective extracted deformation from the interferogram along a longitudinal line on the ice tongue. It compares to the kind of deflection expected by the model (westward and eastward flexure on the same graph). 


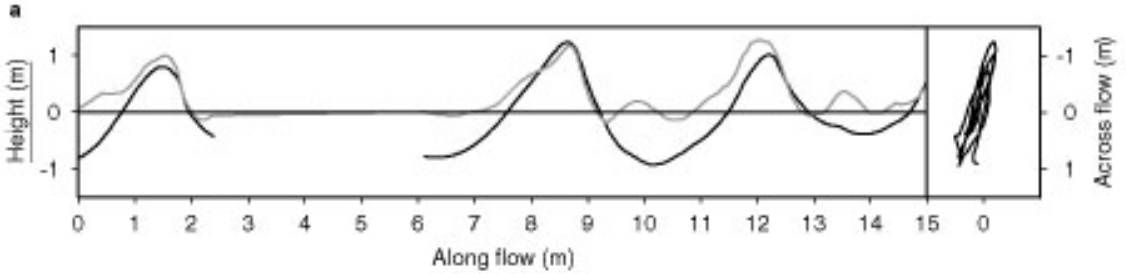

b velocly vs tidal height change
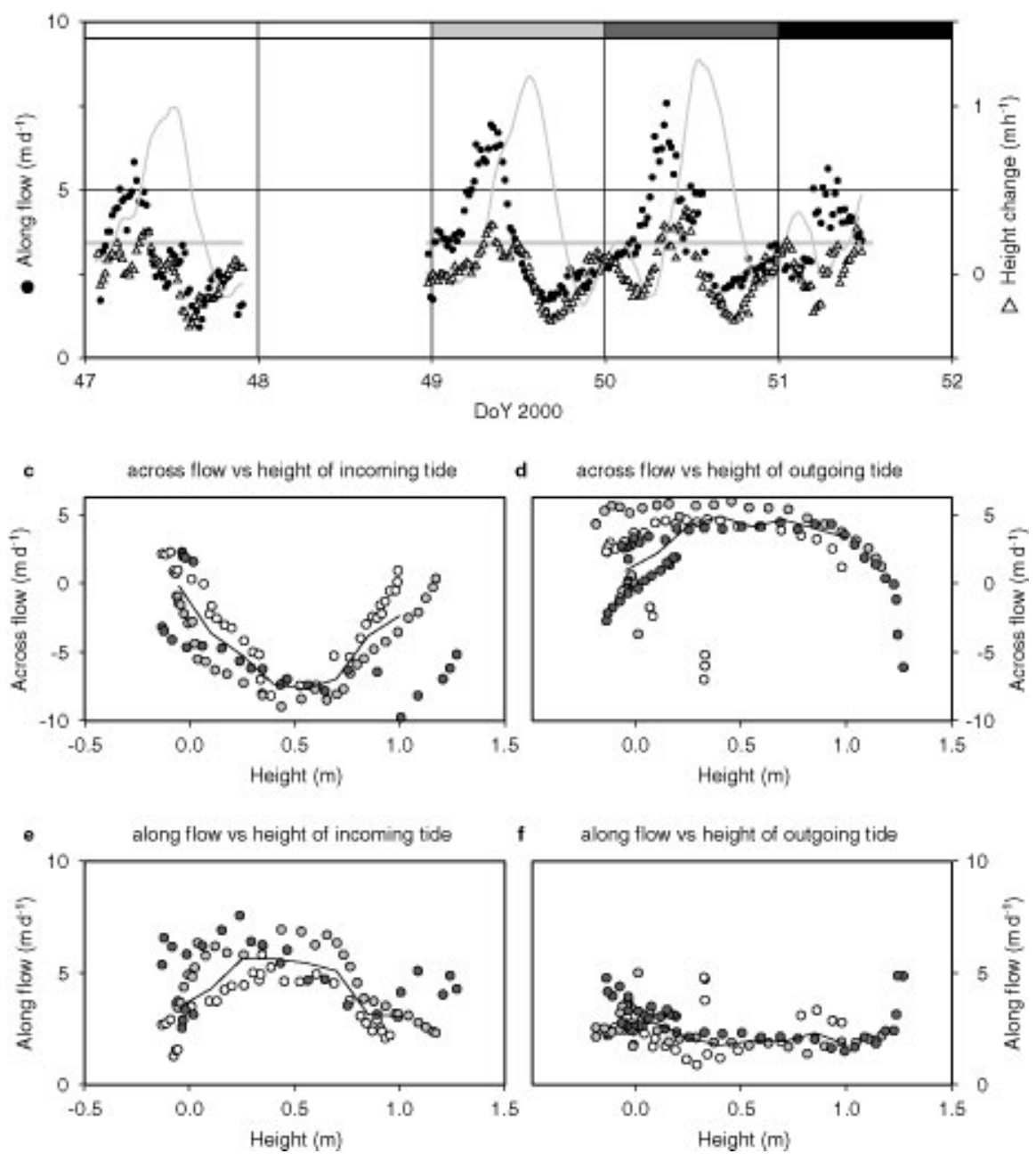

Fig. 6. GPS measurements on the ice tongue. The measurement point is situated at the edge of the tongue (Fig. 1). (a) The horizontal position along the 4 days of observation. Abscissa is along-flow distance from the first measurement; ordinates are acrossflow distance (dark lines) and height (light lines). The right-side plots correspond to the same along-/across-flow position, but with the average velocity component removed. (b) The height level (light grey lines), along-flow velocity (black dots) and height change or time derivative of the height (triangles). DoY, day of year. $(c, d)$ The across-flow position vs the height level for ascending $(c)$ and descending tides $(d)$. + / values correspond to eastward/westward respectively. Different dots shades correspond to different days of observation. $(e, f)$ The along-flow speed vs the height level for ascending $(e)$ and descending tides $(f)$.

However, the double-difference interferogram corresponds to the difference of four epochs, each having its own flexure. In this study, we do not have actual ocean current values for each epoch. It is thus impossible to reproduce a reliable flexure model comparable to this particular line. None of the tide levels for the $\mathrm{I}_{2}$ acquisitions corresponds to very significant tidal currents. The April interferogram shows both acquisitions have similar tide levels separated by 1 day, so there must be a similar current, whereas the May interferogram has two high-tide acquisitions, which have a near-zero tidal current and thus a small current difference. It is thus logical that there are few fringes on this double difference, although a few fringes are always observed on individual interferograms which compensate each other.

\subsection{Horizontal bending from GPS observations}

In Figure 6 we show different representations of the GPS data acquired during 3 days of observations. Although short, this record is sufficient for several important conclusions to be drawn. Figure 6 a shows the kinematic positions of the GPS beacon in along-flow and across-flow directions. According to our processing scheme, and given that we are in a polar region and the horizontal movements we find are larger than in the vertical, these positions cannot result from processing artefacts (King and others, 2003). The right panel is the same with mean velocity removed. One can see there is both an across-flow movement and an along-flow movement modulation and they are linked so the along-flow 
movement increases when a westward shift occurs, and decreases when the tongue shifts eastward. Figure $6 \mathrm{~b}$ shows the vertical position and velocity (or derivative of the height position) as well as the horizontal along-flow ice velocity. It clearly appears that the along-flow speeds are in agreement with the water-level variations. The ice flows at up to $7 \mathrm{~m} \mathrm{~d}^{-1}$ during ascending tides and slows down to $2 \mathrm{~m} \mathrm{~d}^{-1}$ during descending tides.

\subsection{Across-flow movement}

From the GPS observations, we can draw the conclusion that ascending tides correspond to a westward movement while descending tides lead to an eastward movement of the tongue. This is confirmed by the representation in Figure $6 \mathrm{c}$ and $\mathrm{d}$. A positive derivative of the vertical position corresponds to ascending tides (Fig. 6c), and a negative derivative to descending tides (Fig. 6d). Positive across-flow displacement corresponds to eastward movements. For incoming tides, a large westward displacement occurs (with a peak around medium tide) while smaller (and more widely spread) displacement occurs eastward during descending tides.

To explain the difference between eastward and westward movement, we must go back to the horizontal bending modelling. Looking at both the interferogram from Figure 2 and the amplitude image in Figure 1, one can see that there are a few kilometres of pack ice or dead ice between the western side of the valley in which the tongue develops and the western side of the 'active tongue' (the one defined with the two flowlines originating from the grounding line at the back of the glacier). This dead ice must be fractured by the movements of the tongue, and the group of visible large cracks indicates that it must be very weakly resistant to the tongue pressure. By contrast, the eastern side of the tongue seems to join the coast wall, which runs straight over $>20 \mathrm{~km}$, and in particular the eastern flowline seems to "touch" the valley side just at the end before the shoreline. If so, the lateral movement is stopped by this wall. This is what we modelled in Figure 4 as the second negative solution. We apply the same $1 \mathrm{~m} \mathrm{~s}^{-1}$ lateral tidal current but now in the eastward direction and we add boundary conditions $y=0$ and $\mathrm{d} y / \mathrm{d} x=0$ at $x=75 \mathrm{~km}$ to simulate the contact of the tongue with the western side rock. In this case, the horizontal bending is more limited (five times less than in the westward direction). This new boundary condition, which may not be so strict in reality, explains very well the difference between eastward and westward movement observed with the GPS data (factor 2-3).

\section{ALONG-FLOW MOVEMENT MODULATION BY TIDES}

Although Figure 6a shows more peaky westward movements, Figure $6 \mathrm{~b}$ shows the horizontal velocity is much larger during ascending tides. Figure $6 \mathrm{e}$ and $\mathrm{f}$ show the along-flow velocity variations during ascending and descending tides respectively. As in the across-flow bending case, the along-flow increase is large and peaky during the ascending tides while it is quite constant during descending tides. The flow-speed modulation by the tide is very important (a factor of 3). We do not observe a large impact on the interferograms since the satellite track is almost parallel to the tongue. The angle between the satellite track and the tongue flow direction is only $6^{\circ}$. Thus the projection of the along-flow velocity as seen by the satellite is small. Interferograms do measure the movement of the targets integrated over the 24 hour period. Thus, even if one of the two interferograms used to form $\mathrm{I}_{1}$ (Fig. 5a) compounds a longer period with high velocity, the difference in accumulated displacement may not be very important. It can be a few tens of $\mathrm{cm}$. In this case, the projection in the satellite lineof-sight direction would be a few $\mathrm{cm}$, i.e. a maximum of two or three fringes. At present, we do not have enough precise elements available to discriminate these fringes in $\mathrm{I}_{1}$ from the lateral bending fringes.

What we observe on single- and double-difference interferograms is the existence of ripples on the phase picture near $67.5^{\circ} \mathrm{S}, 144.75^{\circ} \mathrm{E}$. These ripples are not always present at exactly the same position. They are in the middle of the tongue and correspond approximately to the limit of influence of the shoreline or to the east side position where the tongue is in contact with the rock as discussed above. They also correspond to the end of the large opening in the ice on the western side, and to the origin of the series of transverse crevasses, which can be seen in Figure 1. These crevasses are parallel to each other and limited by two main longitudinal fractures, which are visible up to the edge of the tongue. On the western side of the western longitudinal fracture and on the eastern side of the eastern fracture, Figure 1 shows crevasses developing at a $45^{\circ}$ angle relative to the direction of main flow or of the longitudinal fractures. These last crevasses must come from the natural spreading of the ice, free of external stress.

The large variations of the flow speed in phase with tidal cycles may be linked to a variation in friction of the ice on the eastern rocky wall.

The next explanation is more speculative and would need more data to verify but it may well explain our observations correctly. During descending tides, the tidal current pushes the tongue toward the eastern rocks, which increases the friction so that the flow speed is reduced; stress accumulates on the ice with speeds at $\sim 700 \mathrm{~m} \mathrm{a}^{-1}$ instead of the $\sim 1200 \mathrm{~m} \mathrm{a}^{-1}$ of the natural regime. When the pressure is released, ascending tides push the tongue westward and eliminate the east side friction. The accumulated stress can be elastically released through an increased speed of up to $\sim 2400 \mathrm{~m} \mathrm{a}^{-1}$, much greater than the natural flow regime. These strike slip cycles can be assured within the elastic hypotheses since the displacement during the period of the ascending tide is within $1 \mathrm{~m}$. This is the same order of magnitude as the flexure created either laterally by the current or vertically by the tides. The elastic assumption is thus able to explain the tongue behaviour we observe. If no elastic condition prevails, the tongue could be curved as suggested by the Holdsworth (1982) measurements for the Erebus ice tongue following the non-symmetry between the eastern and western sides. The existence and development of crevasses indicates that the deformation must be plastic. Formulation in terms of effective thickness or width, as developed by Lingle and others (1981), should help conciliate the elastic behaviour with the important crevassing of the tongue.

\section{GONGLUSION}

A number of remotely sensed datasets, including in situ GPS measurements, satellite radar altimetry, airborne 
radio-echo sounding and satellite SAR imagery and interferometry, were used to study the Mertz Glacier tongue. With these data, we studied the movement of the ice tongue, both vertically and along and across the flow direction. We show that tidal currents, which operate along the GeorgeV Coast, must exert a significant pressure on the tongue to create its observed flexure. A simple model of the pressure forces and their integration helped us compute the elastic flexure resulting from the lateral pressure of tidal currents. GPS observations confirm that a boundary condition must be added on the eastern side of the fjord, where the lateral flexure of the tongue must be stopped by rigid rocks. Finally, observations of the temporal variation of the along-flow movement linked to the tidal signal suggest that this lateral pressure on the tongue changes the friction of the tongue on the eastern side of the fjord and makes the alongflow velocity vary temporally in phase with the tides.

This kind of study must be improved with a better specification of all of the forces and boundary conditions acting on the floating ice sections. Dedicated tidal height and current modelling would help improve our understanding of the action of the tidal currents on the tongue. Drag coefficients could be studied, as well as our assumption that the elastic modulus adopted is satisfactory. Further GPS observations, which would include an array of GPS receivers at several points on the Mertz Glacier tongue, would better describe the coupling between tides (or sea-level variations), boundary conditions and ice flow. They may explain the coupling observed between the tides and the ice flow in this area and on other floating ice shelves or ice streams of Antarctica. Coupled modelling of the floating ice as proposed by Schmeltz and others (2002), if applied to Mertz Glacier including the lateral boundary and flow conditions we observe here, would help greatly to improve our knowledge of the Antarctic outlet glacier dynamics. Finally, this kind of study may help better describe the mechanics of floating ice and be a basis for studying more precisely the calving of giant icebergs.

\section{AGKNOWLEDGEMENTS}

We would like to thank R. Morrow of the Laboratoire d'Etudes en Géophysique et Océanographie Spatiale (Legos), France, and R. Coleman of the University of Tasmania, Australia, who helped improve the English and provided very helpful pre-review. Two reviewers made constructive comments which helped improve the manuscript.

\section{REFERENGES}

Anandakrishnan, S., D. E. Voigt, R. B. Alley and M. A. King. 2003. Ice Stream D flow speed is strongly modulated by the tide beneath the Ross Ice Shelf. Geophys. Res. Lett., 30(7), 1361. (10.1029/2002GL016329.)

Barnes, P. W. 1987. Morphologic studies of the Wilkes Land continental shelf, Antarctica: glacial and iceberg effects. In Eittreim, S. L. and M. A. Hampton, eds. The Antartic continental margin: geology and geophysics of offshore Wilkes Land. Houston, TX, Circum-Pacific Concilium for
Energy and Mineral Resources, 175-193. (CPCEMR Earth Science Series 5a.)

Beutler, G. and 11 others. 2001. Bernese GPS software. Version 4.2. Berne, University of Berne. Astronomical Institute.

Bindschadler, R. A., M. A. King, R. B. Alley, S. Anandakrishnan and L. Padman. 2003a. Tidally controlled stick-slip discharge of a West Antarctic ice stream. Science, 301 (5636), 1087-1089.

Bindschadler, R. A., P. L. Vornberger, M. A. King and L. Padman. 2003b. Tidally-driven stick-slip motion in the mouth of Whillans Ice Stream, Antarctica. Ann. Glaciol., 36, 263-272.

Doake, C.S. M. and 6 others. 2002. Tide-induced lateral movement of Brunt Ice Shelf, Antarctica. Geophys. Res. Lett., 29(8), 1226. (10.1029/ 2001GL014606.)

Domack, E.W. 1987. Preliminary stratigraphy for a portion of Wilkes Land continental shelf, Antarctica: evidence from till provenance. In Eittreim, S. L. and M. A. Hampton, eds. The Antarctic continental margin: geology and geophysics of offshore Wilkes Land. Houston, TX, Circum-Pacific Concilium for Energy and Mineral Resources, 195-204. (CPCEMR Earth Science Series 5a.)

Domack, E.W. and J. B. Anderson. 1983. Marine geology of the George V continental margin: combined results of the Deep Freeze 79 and the 1911-1914 Australian expedition. In Oliver, R. L., P. R. James and J. B. Jago, eds. Antarctic earth science. Cambridge, etc., Cambridge University Press. Australian Academy of Science, 402-406.

Frezzotti, M., A. Cimbelli andJ. G. Ferrigno. 1998. Ice-front change and iceberg behaviour along Oates and George V Coasts, Antarctica, 1912-96. Ann. Glaciol., 27, 643-650.

Holdsworth, G. 1969. Flexure of a floating ice tongue. f. Glaciol., 8(54), 385-397.

Holdsworth, G. 1982. Dynamics of Erebus Glacier tongue. Ann. Glaciol., 3, 131-137.

Holdsworth, G. 1985. Some effects of ocean currents and wave motion on the dynamics of floating glacier tongues. In Jacobs, S. S., ed. Oceanology of the Antarctic continental shelf. Washington, DC, American Geophysical Union, 253-271. (Antarctic Research Series 43.)

King, M. A., R. Coleman and L. N. Nguyen. 2003. Spurious periodic horizontal signals in sub-daily GPS position estimates. f. Geod., 77(1-2), $15-21$.

Korth, W. 2001. Realization of the geodetic and gravimetric project. In Bozzo, A. and D. Damaske, eds. GANOVEX VIII-ITALIANTARTIDE XV Antartic Expedition 1999-2000, 103-108. (Terra Antarctica Reports No. 5.)

Lefevre, F., F. H. Lyard, C. le Provost and E. J. O. Schrama. 2002. FES99: a global tide finite element solution assimilating tide gauge and altimetric information. 7. Atmos. Ocean. Tech., 19, 1345-1356.

Legrésy, B. and F. Rémy. 1997. Altimetric observations of surface characteristics of the Antarctic ice sheet. F. Glaciol., 43(144), 265-275. (Erratum: 43 (145), p. 596.)

Lingle, G. S., T. J. Hughes and R. C. Kollmeyer. 1981. Tidal flexure of Jakobshavns glacier, West Greenland. f. Geophys. Res., 86(B5), 3960-3968.

Pötzsch, A., B. Legrésy, W. Korth and R. Dietrich. 2000. Glaciological investigations of Mertz Glacier, East Antarctica, using SAR interferometry and field observations. In ERS-ENVISAT Symposium "Looking down to Earth in the New Millennium", 16-20 October 2000, Gothenburg, Sweden. Proceedings. Noordwijk, European Space Agency, CD-ROM/500poetz.pdf. (ESA SP-461.)

Rabus, B. T. and O. Lang. 2002. On the representation of ice-shelf grounding zones in SAR interferograms. F. Glaciol., 48(162), 345-356.

Riedel, B., U. Nixdorf, M. Heinert, A. Eckstaller and C. Mayer. 1999. The response of the Ekströmisen (Antarctica) grounding zone to tidal forcing. Ann. Glaciol., 29, 239-242.

Rignot, E. 1996. Tidal motion, ice velocity and melt rate of Petermann Gletscher, Greenland, measured from radar interferometry. 7. Glaciol., 42(142), 476-485.

Schmeltz, M., E. Rignot, T. K. Dupont and D. R. MacAyeal. 2002. Sensitivity of Pine Island Glacier, West Antarctica, to changes in ice-shelf and basal conditions: a model study. f. Glaciol., 48(163), 552-558.

Vaughan, D. G. 1995. Tidal flexure at ice shelf margins. 7. Geophys. Res., 100 (B4), 6213-6224.

Wendler, G., K. Ahlnäs and C. S. Lingle. 1996. On Mertz and Ninnis Glaciers, East Antarctica. 7. Glaciol., 42(142), 447-453. 